\title{
Prácticas de consumo y estilo de vida de la población LGTB* de Bogotá*
}

\section{Consumption practices and lifestyle of LGBT group of Bogotá}

\author{
Idaly Barreto*** \\ Marithza Sandoval \\ Omar Fernando Cortés \\ Fundación Universitaria Konrad \\ Lorenz, Bogotá, Colombia \\ Recibido: 22 de septiembre de 2009 \\ Revisado: 26 de octubre de 2009 \\ Aceptado: 15 de diciembre de 2009
}

\section{Resumen}

El presente estudio corresponde a un diseño no experimental transeccional con niveles de análisis descriptivo, comparativo y correlacional de los subgrupos de la población LGBT y de la población heterosexual residente en la ciudad de Bogotá, Colombia. Se elaboró una encuesta y se aplicó a 639 personas de la comunidad LGBT y heterosexual, con el propósito de identificar las prácticas de consumo (patrón de gastos en vivienda, servicios públicos, hogar, etc.) y estilo de vida (prácticas deportivas y esparcimiento, entre otras). Los resultados muestran que existen diferencias en el estilo de vida entre los grupos del colectivo LGBT, y entre éste y los heterosexuales. No obstante, estas diferencias son específicas y no pueden atribuirse exclusivamente a la orientación sexual. En lo que se refiere a las prácticas de consumo se encontró que existen muchas más similaridades que diferencias entre mujeres y hombres homosexuales en comparación con sus contrapartes heterosexuales, indicando que el consumo está más asociado con variables de tipo demográfico que con la orientación sexual como tal.

Palabras clave: psicología del consumidor, consumo, LGBT.

\footnotetext{
La sigla LGBT se refiere a lesbianas, gays, bisexuales y transexuales.

** Proyecto de investigación institucional financiado por la Fundación Universitaria Konrad Lorenz (2007 - 2008). Adscrito a la línea de investigación de procesos socioculturales y prácticas de consumo del Grupo de Investigación en Psicología del Consumidor.

*** Correspondencia: Idaly Barreto. Doctora en Psicología. Facultad de Psicología. Maestría en Psicología del Consumidor. Fundación Universitaria Konrad Lorenz. Carrera 9 Bis No. 62-43. Bogotá-Colombia. Correo electrónico: idaly.barretog@fukl.edu.
} 


\section{Abstract}

This study corresponds to a trans-sectional non-experimental design with descriptive levels of analysis, comparison and correlation of the subgroups of the LGBT population and the heterosexual population resident in the city of Bogota-Colombia. A survey was constructed and applied to 639 people from the LGBT community and heterosexual in order to identify the practices of consumption (expenditure pattern of housing, utilities, home, etc.) and lifestyle (sporting and recreational among others). The results show that there are differences in lifestyle between LGBT groups and between it and heterosexuals. However, these differences are specific and not attributable solely to sexual orientation. In regard to consumption practices found that there are many more similarities than differences between women and gay men compared with their heterosexual counterparts, indicating that consumption is more associated with type of demographic variables to sexual orientation as such.

Key words: consumer psychology, consumption, LGBT.

\section{Introducción}

Desde el surgimiento y desarrollo del movimiento LGBT en el mundo, diversas comunidades científicas se han interesado por investigar la relación existente entre el consumo y la orientación sexual de las personas. En la década de los noventa, algunas investigaciones concluyeron que estas diferencias se presentaban de manera significativa y que se relacionaban con los comportamientos de riesgo (Burnett, 2000). Incluso, se generaron estereotipos asociados con la homosexualidad, esta vez en relación con el consumo. Así por ejemplo, se considera que las personas gay están siempre a la vanguardia y que son innovadoras, conformando lo que en muchas agencias y organizaciones se ha denominado el "mercado rosa".

Vandercasteele \& Geuens (2009) coinciden en que existe realmente poca evidencia para realizar una clasificación estereotipada del consumo del colectivo LGBT y que la evidencia disponible es pseudocientífica. Esto sucede debido a que el particularizar una tendencia de consumo, exige obligatoriamente la comparación con los grupos de orientación heterosexual, lo cual no siempre es el caso. El estudio de estos autores sobre innovación en el consumo, muestra que los hombres homosexuales aventajan a los hombres heterosexuales en la compra de productos innovadores. De otra parte, las mujeres lesbianas del estudio son menos innovadoras que las mujeres hetero- sexuales. Los resultados evidencian que aunque no en todos los factores y productos analizados se presentan estas diferencias, al menos en lo referente a compra de productos únicos o exclusivos y en los comportamientos asociados a búsqueda y evaluación innovadora, las mujeres y hombres homosexuales difieren significativamente de sus contrapartes heterosexuales. Un aspecto importante es que estas diferencias están mediadas por el contexto familiar y las variables demográficas. Así por ejemplo, la diferencia entre mujeres lesbianas y heterosexuales desaparece cuando se trata de mujeres que viven con sus padres. Casi todos los participantes estuvieron de acuerdo con que las particularidades de su consumo se relacionaban más con sus condiciones de vida inherentes al hecho de tener una vida homosexual, que a su orientación sexual propiamente dicha.

En otra línea de indagación, se han encontrado diferencias en la compra de casas, comparando parejas heterosexuales y parejas del mismo sexo en los Estados Unidos; las parejas homosexuales compran menos veces casas que sus contrapartes heterosexuales, cuando las compran son de menor valor y tienden a involucrarse menos en hipotecas (Jepsen \& Jepsen, 2009).

Además de la innovación y del endeudamiento, se han realizado estudios para identificar diferencias 
respecto a la satisfacción con la imagen corporal, así como el consumo de alcohol y drogas. En el meta-análisis realizado por Morrison, Morrison \& Sager (2004) se encontraron diferencias muy leves en la satisfacción con la imagen corporal, dependiendo de la orientación sexual de las personas, observándose una mejor imagen corporal en hombres heterosexuales que en hombres gay. No se identificaron diferencias significativas en la satisfacción con la imagen corporal entre mujeres heterosexuales y mujeres lesbianas. Los resultados de este meta-análisis sugieren además, que los hombres gay son más vulnerables a la insatisfacción corporal que los demás grupos. Esto apoya en parte la idea de la existencia de un "mercado rosa", de manera que algunas empresas han empezado a desarrollar estrategias dirigidas a hombres heterosexuales, para impulsar la compra de artículos asociados con la belleza, el cuidado personal y la moda, los cuales han sido clasificados como parte del mercado gay (Tuncay \& Otnes, 2008). Esto debido a que el mercado de hombres no gay es mucho más grande que el "mercado rosa".

En cuanto al consumo de cigarrillo y alcohol, los estudios indican que comparados con los heterosexuales, las personas LGBT muestran mayor consumo de cigarrillo, pero en cuanto a las actitudes frente a éste, no se presentan diferencias entre homosexuales y heterosexuales (Pizcani et al., 2009). Comparadas con las mujeres heterosexuales, las bisexuales y lesbianas tienen más probabilidad de consumir alcohol, no propiamente por su orientación sexual, sino porque su condición genera aun más rechazo que a los hombres gay y porque es común haber experimentado múltiples episodios de violencia. Adicionalmente, por la necesidad de buscar espacios de homosocialización donde el alcohol y el cigarrillo son comunes (Ortiz-Hernández, Gómez \& Valdez, 2009). De la misma manera, parece que las mujeres bisexuales pueden presentar mayor incidencia de consumo de alcohol y drogas que las mujeres heterosexuales (Tucker, Ellickson \& Klein, 2008). No obstante, ¿se puede asumir que estas diferencias se relacionan con la orientación sexual? La respuesta no es simple y requiere del desarrollo sistemático de investigaciones conducentes no sólo a un mejor conocimiento de la población LGBT, sino también al desarrollo de políticas de fomento o prevención del consumo (según sea el caso y la problemática social implicada), sobre bases reales, más que sobre estereotipos creados por los grupos sociales a favor o en contra de este movimiento.

En el contexto colombiano, Giraldo \& Alvarado (2006); Alvarado, Botero, Giraldo \& Dávila (2005) realizaron un estudio sobre compra impulsiva. El objetivo de éste fue describir las características de la compra impulsiva del homosexual masculino de la ciudad de Barranquilla, a través de la identificación de productos, servicios, marcas y establecimientos más demandados por este grupo. En su mayoría las investigaciones sobre población LGBT están orientadas tanto a descubrir y describir el estilo de vida de la población como a desmitificar creencias e imaginarios sociales (Barrea y Olivera, 2004) relacionados con la homosexualidad.

Como se mencionaba antes, el interés por el consumo de la población LGBT obedece, en algunos casos, a los beneficios recibidos por las firmas al encontrar nuevos mercados en segmentos que consumen productos y servicios en una proporción importante (sólo en EE.UU. 600 billones de dólares), pero que no se han reconocido abiertamente como mercados formales y potentes. Aunque no se cuenta con un dato objetivo respecto al aporte de la población LGBT en millones de pesos a la economía nacional, es claro que su fuerza es cada vez mayor. Específicamente en la capital (Bogotá, D.C.), la población LGBT se ha convertido en un grupo de consumo importante en mercados de entretenimiento, moda, arreglo personal, turismo y educación, entre otros. Este interés contrasta con el rechazo que muestran muchas organizaciones LGBT ante los estudios de sus patrones de comportamiento, rechazo asociado con la posibilidad de ser manipulados a partir del conocimiento de sus preferencias, estilos de vida y patrones de compra. Pero más allá del criterio de marketing, lograr el reconocimiento del colectivo LGBT como unidad o unidades de consumo, permite que en muchos sentidos se genere una legitimación del consumo que realizan y se respeten abiertamente sus derechos como consumidores, en contravía con el denominado heterosexismo institucional (O’Brien, 2001). 
Con este propósito de reconocimiento de la población LGBT como comunidad de consumo, es necesario comprender el entorno social y cultural que tiene el consumidor a partir de la información proporcionada por ellos mismos. En este contexto sociocultural, los estudios sobre grupos de referencia (Vélez, 2002) como agentes de influencia en las prácticas de consumo, están orientados al análisis de los comportamientos de compra en diferentes tipologías de grupos, en principio la familia y los amigos. Lo anterior, se fundamenta en la necesidad que tienen los seres humanos de interactuar socialmente con otras personas y que, desde la psicología del consumidor tiene aspectos relevantes que considerar.

En primer lugar, es preciso comprender las creencias que comparten los grupos para así identificar por qué se adscriben a determinados estilos de vida con el propósito, en algunos casos, de formar o mantener un grupo de amigos (as). En segundo lugar, y a partir de la identificación con un grupo en particular, es necesario identificar y comprender prácticas culturales que se vinculan con la definición de roles sociales, patrones culturales y subculturales. En este sentido, el estudio de los grupos y la cultura, tal y como lo plantea Moreno (2005), aportan una visión complementaria para la investigación de mercados y privilegian la organización y descripción de las relaciones de interacción presentes en los grupos con estructuras de función y significado permitiendo la comprensión de las prácticas de consumo desarrolladas por diferentes grupos. Con este interés, el presente proyecto pretendió caracterizar el estilo de vida y los patrones de consumo de la población LGTB de la ciudad de Bogotá paralelo a un grupo de hombres y mujeres heterosexuales.

\section{Método}

\section{Tipo de investigación}

El presente estudio corresponde a un diseño no experimental, transeccional con niveles de análisis descriptivo, comparativo y correlacional de los subgrupos de la población LGBT y de población heterosexual.

\section{Participantes}

Dada la ausencia de datos estadísticos acerca del tamaño aproximado de la población LGBT en la ciudad de Bogotá, se realizaron 639 encuestas en un período de 2 meses calendario (mayo - junio, 2008). Esta muestra cuenta con un $95 \%$ de confiabilidad y $3.8 \%$ de error. Se contó con la participación de 76 lesbianas $(11.89 \%), 163$ gays (25.5\%), 31 mujeres bisexuales (4.9\%), 41 hombres bisexuales $(6.4 \%)$, 32 transexuales (5\%), 153 mujeres heterosexuales (23.9\%) y 143 hombres heterosexuales (22.4\%).

\section{Técnicas e instrumentos de recolección de información}

Se elaboró una encuesta con el propósito de identificar las prácticas de consumo de la comunidad LGBT y heterosexual, e incluyó aspectos demográficos (ocupación, identidad de género, edad, estrato, lugar de nacimiento, número de hijos, estado civil, nivel educativo, rango de ingresos mensuales y número de personas con quienes vive), estilo de vida, prácticas deportivas, esparcimiento y patrón de gastos.

\section{Procedimiento}

El estudio inició con el acercamiento a la población LGTB para establecer contactos con personas pertenecientes al grupo LGBT y para determinar los lugares comúnmente frecuentados por ellos, y así solicitar su participación voluntaria en la investigación. Posteriormente, se plantearon agrupaciones temáticas referentes al estilo de vida y prácticas de consumo que orientaron el diseño del instrumento de recolección de información. La aplicación de las encuestas se realizó de manera individual con una duración promedio de una hora.

\section{Análisis de datos}

Para el análisis de los datos se utilizaron estadísticos descriptivos con medidas de tendencia central y dispersión. Se generaron tablas personalizadas y se calcularon pruebas de comparación de promedios e índices de correlación de tipo Kendall Tau, Spearman y Pearson. 


\section{Resultados}

Dentro de los resultados derivados del estudio sobre estilo de vida y prácticas de consumo de la población LGBT, se presenta a continuación la caracterización general de los participantes y posteriormente la descripción de los aspectos relacionados con los estilos de vida y las prácticas de consumo para cada una de las siete submuestras correspondientes a los grupos de lesbianas, gay, bisexuales, transexuales y heterosexuales.

\section{Descripción socio-demográfica}

En la Tabla 1 se presentan los porcentajes al interior de cada grupo por identidad de género y nivel socioeconómico (NSE). El segmento socioeconómico clasificado en las categorías de bajo (incluye niveles socioeconómicos 1 y 2), medio ( 3 y 4 ) y alto (5 y 6). El segmento socioeconómico -clasificado en las categorías de bajo (1.2), medio (3.4) y alto (5.6)- de mayor porcentaje en la muestra es el medio $(76.5 \%)$, con una proporción menor para los NSE bajos y altos (13.5\% - 10\%).

Tabla 1. Distribución porcentual de la muestra por identidad de género y nivel socioeconómico

\begin{tabular}{lcccc}
\hline & \multicolumn{3}{c}{ Nivel Socio Económico } & Total \\
\cline { 2 - 4 } & Bajo & Medio & Alto & \\
\hline Lesbiana & $13.2 \%$ & $73.7 \%$ & $13.2 \%$ & $100 \%$ \\
Gay & $12.9 \%$ & $78.5 \%$ & $8.6 \%$ & $100 \%$ \\
Bisexual (masculino) & $9.8 \%$ & $73.2 \%$ & $17.1 \%$ & $100 \%$ \\
Bisexual (femenino) & $22.6 \%$ & $58.1 \%$ & $19.4 \%$ & $100 \%$ \\
Heterosexual (masculino) & $10.6 \%$ & $83.8 \%$ & $5.6 \%$ & $100 \%$ \\
Heterosexual (femenino) & $13.2 \%$ & $78.3 \%$ & $8.6 \%$ & $100 \%$ \\
Transexual & $28.1 \%$ & $53.1 \%$ & $18.8 \%$ & $100 \%$ \\
\hline Total & $13.5 \%$ & $76.5 \%$ & $10.0 \%$ & $100 \%$ \\
\hline
\end{tabular}

Frente al nivel educativo, el $50.2 \%$ del total de la muestra tiene estudios de nivel universitario. La mayor participación en este nivel educativo es para el grupo de hombres $(67.7 \%)$ y mujeres (53.7\%) bisexuales, seguido por el grupo de mujeres $(53.3 \%)$ y hombres $(51.1 \%)$ heterosexuales. Como tendencia general, el $73.4 \%$ de los participantes es soltero (a), constituyéndose como el estado civil más prevalente en cada uno de los siete subgrupos y siendo significativamente mayor para el caso de los hombres bisexuales con un $82.9 \%$, los gay con un $81.6 \%$, las mujeres bisexuales con el $80.6 \%$ y las lesbianas con un $78.7 \%$. Solo un $21.1 \%$ de la muestra general de participantes reporta que tiene hijos, observando las mayores participaciones para los casos de los hombres heterosexuales con un $31.2 \%$ y las mujeres heterosexuales con el $35.9 \%$.

Tabla 2. Descripción de la edad por identidad de género

\begin{tabular}{lllll}
\hline & Media & Desviación típica & Percentil 25 & Percentil 75 \\
\hline Lesbiana & 25.6 & 6.34 & 21.0 & 30.0 \\
Gay & 28.1 & 8.34 & 22.0 & 32.0 \\
Bisexual (masculino) & 26.5 & 6.98 & 22.0 & 30.0 \\
Bisexual (femenino) & 24.4 & 4.60 & 21.0 & 28.0 \\
Heterosexual (masculino) & 28.6 & 9.13 & 22.0 & 34.0 \\
Heterosexual (femenino) & 27.5 & 8.39 & 22.0 & 32.0 \\
Transexual & 31.6 & 6.15 & 29.0 & 37.0 \\
\hline Total & 27.7 & 8.10 & 22.0 & 32.0 \\
\hline
\end{tabular}


Tal como se aprecia en la Tabla 2, el promedio de edad de los participantes es de 27 años con una tendencia central estimada entre los 22 y 32 años. El promedio menor de edad se encuentra en las mujeres bisexuales con 24 años, mientras que el promedio superior de edad se observa para el caso de los transexuales con 31 años. El 48.2\% de los participantes está actualmente empleado, un $25.4 \%$ son estudiantes, el $16.8 \%$ se dedica a actividades independientes y un $7.1 \%$ estudia y trabaja, entre otros. El núcleo familiar de los participantes está constituido por 3 personas, oscilando entre 2 y 4 personas como tendencia central.

\section{Estilo de vida y prácticas de consumo del grupo de lesbianas}

Las principales actividades semanales identificadas en el estilo de vida de este grupo de mujeres (Tabla 3) son: trabajar (38.5 horas), dormir (36.8 horas), estudiar (25.2 horas), escuchar música
(20.4 horas) y dedicar tiempo a la familia (20.4 horas). Por nivel económico se observan diferencias estadísticamente significativas como la mayor cantidad de tiempo dedicado a la familia en el estrato bajo en comparación con los estratos medio y alto; el tiempo dedicado al salón de belleza en el estrato alto en comparación con los estratos medio y bajo y; la asistencia a bares en el estrato bajo en comparación con los estratos medio y alto. Las correlaciones significativas identificadas al $99 \%$ que se encuentran entre las diferentes actividades son: ir al cine y salón de belleza ( $r$ : 0.69), ir a video bares e ir al cine (r: 0.65), ir al gimnasio e ir al salón de belleza ( $r: 0.61)$, ir de compras e ir al salón de belleza (r. 0,91), ir a bares e ir al salón de belleza ( $r: 2.07)$, ir a bares e ir al cine ( $r: 0.67)$, ir a cafés y hacer deporte ( $r: 0.64)$, leer e ir a restaurantes ( $r$ : 0.58). Dentro los principales hobbies se encuentran los deportes con un $11.8 \%$, las actividades manuales con un $6.6 \%$ y la música con el $5.3 \%$.

Tabla 3. Estilo de vida en el grupo de lesbianas

\begin{tabular}{lcccc}
\hline & \multicolumn{3}{c}{ Nivel socioeconómico } & Total promedio \\
\cline { 2 - 5 } & Bajo & Medio & Alto & semanal \\
\hline Trabajar & 47.6 & 36.4 & 40.4 & 38.5 \\
Familia & 33.4 & 17.4 & 22.4 & 20.4 \\
Ir al cine & 2.0 & 3.5 & 4.4 & 3.6 \\
Salón de belleza & 2.2 & 2.8 & 9.0 & 3.3 \\
Ir al restaurante & 3.0 & 6.9 & 10.5 & 7.2 \\
Dormir & 44.8 & 37.2 & 27.1 & 36.8 \\
Estudiar & 12.6 & 26.3 & 28.4 & 25.2 \\
Hacer deporte & 6.7 & 9.2 & 6.3 & 8.4 \\
Internet & 13.0 & 10.8 & 17.4 & 12.0 \\
Ir a saunas & 1.0 & 3.2 &. & 3.0 \\
Actividades extremas & 3.0 & 2.3 &. & 2.4 \\
Ver televisión & 15.5 & 10.3 & 7.8 & 10.6 \\
Ir a video bares & 5.5 & 5.6 & 5.3 & 5.5 \\
Ir al gimnasio &. & 6.2 & 11.5 & 7.2 \\
Ir de compras & 6.2 & 5.0 & 11.8 & 6.4 \\
Ir a cafés & 4.5 & 5.5 & 7.8 & 5.7 \\
Estar solo & 21.6 & 13.8 & 12.8 & 14.6 \\
Tiempo en pareja & 12.5 & 15.6 & 12.1 & 14.7 \\
Leer & 5.0 & 6.7 & 10.5 & 6.8 \\
Caminar & 5.1 & 7.5 & 4.0 & 6.7 \\
\hline & & & & \\
\hline
\end{tabular}




\begin{tabular}{lcccc}
\hline & \multicolumn{3}{c}{ Nivel socioeconómico } & Total promedio \\
\cline { 2 - 5 } & Bajo & Medio & Alto & semanal \\
\hline Ir a bares & 22.5 & 6.9 & 10.5 & 8.1 \\
Escuchar música & 31.2 & 20.3 & 14.1 & 20.4 \\
Practicar su hobbie & 12.8 & 11.3 & 9.3 & 11.1 \\
\hline
\end{tabular}

En las prácticas deportivas, los juegos de mesa son preferidos por el $27.6 \%$, y principalmente por un $30.4 \%$ del grupo de lesbianas que pertenecen al nivel económico medio. Las danzas son practicadas por el $22.4 \%$ siendo el $30 \%$ de estrato alto; el fútbol es practicado por el $21 \%$ y un $40 \%$ de este porcentaje corresponde a estrato alto; el básquetbol es practicado por el $19.7 \%$ observando porcentajes similares en los estratos medio y bajo, y los aeróbicos también son practicados por un $19.7 \%$ siendo mayor su participación al interior del estrato alto con un $40 \%$.
En la Tabla 4 se observa el patrón general de gastos promedio donde los rubros que tienen una mayor dedicación de recursos económicos son para educación, arriendo, ropa, cuota de vivienda, viajes, préstamos bancarios, $C D$ y películas, cuota de ahorro, tarjetas de crédito y calzado. Cabe anotar que no se encontraron diferencias estadísticamente significativas que se puedan resaltar entre los niveles socioeconómicos por categoría y que los promedios del nivel socioeconómico alto son en varios rubros inferiores a los del nivel medio, porque son los padres quienes asumen los costos de vivienda y alimentación.

Tabla 4. Patrón de gastos mensual promedio para el grupo de lesbianas

\begin{tabular}{|c|c|c|c|c|}
\hline \multirow{3}{*}{$\begin{array}{l} \\
\text { Arriendo }\end{array}$} & \multicolumn{4}{|c|}{ Nivel socioeconómico } \\
\hline & Bajo & Medio & Alto & Total promedio \\
\hline & $\$ 287.500$ & $\$ 394.500$ & $\$ 253.333$ & $\$ 37.1486$ \\
\hline Cuota vivienda & $\$ 130.000$ & $\$ 385.714$ & $\$ 205.000$ & $\$ 324.000$ \\
\hline Energía eléctrica & $\$ 27.833$ & $\$ 72.581$ & $\$ 67.500$ & $\$ 65.537$ \\
\hline Agua/alcantarillado & $\$ 41.429$ & $\$ 96.129$ & $\$ 50.000$ & $\$ 82.619$ \\
\hline Gas & $\$ 32.500$ & $\$ 22.867$ & $\$ 23.333$ & $\$ 23.946$ \\
\hline Educación & $\$ 160.333$ & $\$ 1.125 .545$ & $\$ 522.000$ & $\$ 880.323$ \\
\hline Productos cárnicos & $\$ 26.667$ & $\$ 94065$ & $\$ 55000$ & $\$ 84632$ \\
\hline Productos lácteos & $\$ 40.000$ & $\$ 39.143$ & $\$ 50.000$ & $\$ 40.233$ \\
\hline Frutas y verduras & $\$ 60.000$ & $\$ 54.543$ & $\$ 32.500$ & $\$ 53.159$ \\
\hline Abarrotes & $\$ 70.000$ & $\$ 67.313$ & $\$ 61.000$ & $\$ 66.641$ \\
\hline Licores & $\$ 25.333$ & $\$ 56.513$ & $\$ 44.167$ & $\$ 53.021$ \\
\hline Cigarrillos & $\$ 21.250$ & $\$ 38.792$ & $\$ 11.667$ & $\$ 33.903$ \\
\hline Aseo para el hogar & $\$ 42.000$ & $\$ 44.744$ & $\$ 55.000$ & $\$ 45.313$ \\
\hline Aseo personal & $\$ 30.000$ & $\$ 55.698$ & $\$ 56.000$ & $\$ 52.870$ \\
\hline Productos para su pareja & $\$ 30.000$ & $\$ 55.208$ & $\$ 46.667$ & $\$ 53.393$ \\
\hline Ropa & $\$ 80.000$ & $\$ 427.000$ & $\$ 191.667$ & $\$ 364.778$ \\
\hline Calzado & $\$ 58.000$ & $\$ 155.455$ & $\$ 135.714$ & $\$ 141.556$ \\
\hline$C D$ & $\$ 30.000$ & $\$ 236.000$ & $\$ 62.500$ & $\$ 192.267$ \\
\hline Viajes & . & $\$ 256.471$ & $\$ 460.000$ & $\$ 302.727$ \\
\hline Salud & $\$ 46.000$ & $\$ 90.167$ & $\$ 85.400$ & $\$ 84.091$ \\
\hline Transporte & $\$ 67.333$ & $\$ 87.978$ & $\$ 61.429$ & $\$ 82.638$ \\
\hline Préstamos bancarios & $\$ 476.667$ & $\$ 157.500$ & . & $\$ 294.286$ \\
\hline Tarjetas de crédito & $\$ 140.000$ & $\$ 128.333$ & $\$ 233.333$ & $\$ 161.000$ \\
\hline Cuota de ahorro & $\$ 20.000$ & $\$ 200.000$ & $\$ 173.333$ & $\$ 180.000$ \\
\hline Rumba & $\$ 20.000$ & $\$ 77.306$ & $\$ 111.667$ & $\$ 79.386$ \\
\hline Club & . & $\$ 67.500$ & $\$ 100.000$ & $\$ 70.000$ \\
\hline Televisión & $\$ 30.000$ & $\$ 55.000$ & $\$ 60.000$ & $\$ 51.923$ \\
\hline Tv cable & $\$ 17.500$ & $\$ 41.300$ & $\$ 30.000$ & $\$ 36.769$ \\
\hline Internet & $\$ 26.000$ & $\$ 42.800$ & $\$ 63.500$ & $\$ 43.357$ \\
\hline Combos $^{1}$ & $\$ 75.000$ & $\$ 98.667$ & $\$ 110.000$ & $\$ 98.611$ \\
\hline Otros Gastos & . & $\$ 66.250$ & $\$ 115.000$ & $\$ 76.000$ \\
\hline
\end{tabular}

${ }^{1}$ El Combo se refiere al producto que incluye suscripción por los servicios de teléfono fijo, internet y televisión por cable o digital. 


\section{Estilo de vida y prácticas de consumo en el grupo de mujeres bisexuales}

Tal como se observa en la Tabla 5, las principales actividades que cuentan con los mayores niveles de dedicación semanal de tiempo para las mujeres bisexuales son: trabajar (43.7 horas), dormir (42.6 horas), estudiar (25.1 horas), escuchar música (18.3 horas), tiempo dedicado a la familia (15.9 horas). Adicionalmente, se encuentran diferencias estadísticamente significativas en la actividad de ir a restaurantes, siendo superior en el nivel socioeconómico alto, al igual que el tiempo en pareja y la práctica de algún hobbie. Las principales correlaciones para el trabajo se estable- cen con ir al restaurante $(r: 0.41)$, ver tv $(r: 0.40)$ y de forma inversa para la actividad de caminar ( $r$ :0.45). El tiempo en familia correlaciona especialmente con dormir (r. 0.46), caminar ( $r: 0.60)$ y de manera inversa con el tiempo dedicado al gimnasio ( $r$ :-0.65). El ir al salón de belleza correlaciona de manera sólida con el uso de Internet ( $r: 0.72$ ) y caminar ( $r$ : 0.50). Estudiar correlaciona principalmente con caminar ( $r$ : 0.53), y hacer deporte con escuchar música ( $r$ : 0.68$)$, entre otros. En las prácticas deportivas se resaltan principalmente los juegos de mesa (41.9\%), siendo superior en el nivel socioeconómico medio (50\%), y, adicionalmente, las prácticas de spinning, aeróbicos, natación, ciclismos, danza, futbol, y caminatas cada una con un $16.1 \%$. Un $6.5 \%$ asiste a gimnasios.

Tabla 5. Estilo de vida de las mujeres bisexuales

\begin{tabular}{lcccc}
\hline & \multicolumn{3}{c}{ Nivel socioeconómico } \\
\cline { 2 - 5 } & Bajo & Medio & Alto & $\begin{array}{c}\text { Total promedio } \\
\text { semanal }\end{array}$ \\
\hline Trabajar & & & 47.8 & 43.7 \\
Familia & 46.7 & 40.8 & 16.3 & 15.9 \\
Ir al Cine & 17.1 & 15.1 & 3.0 & 2.5 \\
Salón de belleza & 2.0 & 2.5 & 2.0 & 2.5 \\
Ir al restaurante & 1.8 & 2.9 & 9.4 & 5.0 \\
Dormir & 2.4 & 4.7 & 44.8 & 42.6 \\
Estudiar & 44.7 & 41.1 & 24.1 \\
Hacer deporte & 27.0 & 24.9 & 5.6 \\
Internet & 3.0 & 7.1 & 6.7 & 12.0 \\
Ir a saunas & 8.2 & 11.5 & 16.3 & 1.8 \\
Actividades extremas & 1.0 & 2.0 & 2.0 & 4.2 \\
Ver televisión & & 3.0 & 6.0 & 8.2 \\
Ir a video bares & 9.1 & 7.3 & 9.8 & 5.2 \\
Ir al gimnasio & 5.6 & 5.7 & 2.0 & 7.8 \\
Ir de compras & 1.0 & 11.5 & 7.0 & 4.0 \\
Ir a cafés & 1.8 & 4.8 & 4.8 & 6.4 \\
Estar solo & 5.5 & 6.6 & 6.8 & 13.7 \\
Tiempo en pareja & 10.8 & 11.5 & 21.3 & 14.5 \\
Leer & 10.8 & 12.7 & 24.4 & 10.3 \\
Caminar & 7.3 & 9.8 & 15.5 & 6.1 \\
Ir a bares & 4.5 & 7.0 & 5.5 & 6.3 \\
Escuchar música & 6.5 & 5.2 & 9.3 & 18.3 \\
Practicar su hobbie & 15.3 & 19.8 & 17.0 & 11.7 \\
\hline
\end{tabular}


Tabla 6. Patrón de gastos mensual en el grupo de mujeres bisexuales

\begin{tabular}{|c|c|c|c|c|}
\hline & & Nivel & conómico & \\
\hline & Bajo & Medio & Alto & Total promedio \\
\hline Arriendo & $\$ 350.000$ & $\$ 387.500$ & $\$ 500.000$ & $\$ 400.000$ \\
\hline Cuota vivienda & . & $\$ 290.000$ & . & $\$ 290.000$ \\
\hline Energía eléctrica & $\$ 91.500$ & $\$ 40.778$ & $\$ 46.667$ & $\$ 54.563$ \\
\hline Agua/alcantarillado & $\$ 43.750$ & $\$ 77.144$ & $\$ 34.000$ & $\$ 60.706$ \\
\hline Gas & $\$ 15.500$ & $\$ 33.667$ & $\$ 28.333$ & $\$ 26.846$ \\
\hline Educación & $\$ 245.000$ & $\$ 473.000$ & $\$ 300.000$ & $\$ 395.500$ \\
\hline Productos cárnicos & $\$ 29.000$ & $\$ 43.125$ & $\$ 35.000$ & $\$ 37.333$ \\
\hline Productos lácteos & $\$ 32.000$ & $\$ 31.500$ & $\$ 40.000$ & $\$ 32.647$ \\
\hline Frutas y verduras & $\$ 22.500$ & $\$ 50.000$ & $\$ 60.000$ & $\$ 44.375$ \\
\hline Abarrotes & $\$ 71.250$ & $\$ 46.250$ & $\$ 40.000$ & $\$ 52.500$ \\
\hline Licores & $\$ 52.500$ & $\$ 69.667$ & $\$ 156.000$ & $\$ 84.792$ \\
\hline Cigarrillos & $\$ 105.000$ & $\$ 28.667$ & $\$ 49.333$ & $\$ 48.000$ \\
\hline Aseo para el hogar & $\$ 33.000$ & $\$ 40.778$ & $\$ 98.333$ & $\$ 48.647$ \\
\hline Aseo personal & $\$ 29.000$ & $\$ 48.750$ & $\$ 85.000$ & $\$ 49.250$ \\
\hline Productos para su pareja & $\$ 37.500$ & $\$ 137.143$ & $\$ 40.000$ & $\$ 95.833$ \\
\hline Ropa & $\$ 50.000$ & $\$ 158.571$ & $\$ 250.000$ & $\$ 147.143$ \\
\hline Calzado & $\$ 42.500$ & $\$ 330.000$ & $\$ 125.000$ & $\$ 165.833$ \\
\hline$C D$ & $\$ 30.000$ & $\$ 170.000$ & . & $\$ 86.000$ \\
\hline Viajes & $\$ 175.000$ & $\$ 194.000$ & $\$ 350.000$ & $\$ 208.750$ \\
\hline Salud & $\$ 106.000$ & $\$ 83.778$ & $\$ 50.000$ & $\$ 86.500$ \\
\hline Transporte & $\$ 72.857$ & $\$ 122.714$ & $\$ 162.000$ & $\$ 116.846$ \\
\hline Préstamos bancarios & $\$ 161.000$ & . & $\$ 300.000$ & $\$ 207.333$ \\
\hline Tarjetas de crédito & $\$ 200.000$ & $\$ 150.000$ & $\$ 300.000$ & $\$ 200.000$ \\
\hline Cuota de ahorro & $\$ 50.000$ & $\$ 120.000$ & $\$ 150.000$ & $\$ 118.571$ \\
\hline Rumba & $\$ 50.000$ & $\$ 132.083$ & $\$ 140.000$ & $\$ 115.227$ \\
\hline Club & . & $\$ 55.000$ & $\$ 20.000$ & $\$ 43.333$ \\
\hline Televisión & $\$ 24.000$ & $\$ 34.000$ & . & $\$ 29.000$ \\
\hline Tv cable & $\$ 26.000$ & $\$ 48.500$ & $\$ 100.000$ & $\$ 55.750$ \\
\hline Internet & $\$ 65.000$ & $\$ 56.750$ & . & $\$ 59.500$ \\
\hline Combos & . & $\$ 115.714$ & $\$ 70.000$ & $\$ 105.556$ \\
\hline Otros gastos & . & $\$ 130.000$ & $\$ 25.001$ & $\$ 95.000$ \\
\hline
\end{tabular}

En la Tabla 6 se presenta el patrón general de gastos promedio para el grupo de las mujeres bisexuales, en el que se resalta en primer lugar los gastos de arriendo, seguido por la educación, cuota de vivienda, viajes, préstamos bancarios, tarjetas de crédito, calzado, ropa, ahorros, transporte, rumba y combos de telefonía, Internet y TV. 


\section{Estilo de vida y prácticas de consumo en el grupo de las mujeres heterosexuales}

En la Tabla 7 se observa que las actividades con mayor dedicación de tiempo semanal son: dormir (42.2 horas), trabajar (39.7 horas), estudiar (21.9 horas), tiempo en familia (21.6 horas), Internet (14.3 horas) y el tiempo en pareja (14.3 horas). Las principales correlaciones se encuentran entre ir al trabajo e ir al salón de belleza ( $r$ : 0.36), ir al trabajo y caminar ( $r$ : 0.32), para el caso del tiempo en familia correlaciona con estar sola (r: 0.41), así como ir al cine correlaciona con ir al restaurante ( $r$ : 0.42) y con ir de compras ( $r$ : 0.46). Los principales hobbies corresponden a la práctica de deportes especiales, la música, leer, escribir y actividades artísticas. Las prácticas deportivas de mayor frecuencia en las mujeres heterosexuales son los juegos de mesa con un $23 \%$, siendo superior en el nivel socioeconómico bajo (25\%), seguidos por los aérobicos con el $12.5 \%$, principalmente en nivel socioeconómico alto con el $23.1 \%$, las danzas con el $12.5 \%$ y un mayor reporte en el nivel socioeconómico alto (53\%) y el basquetbol con un $11.2 \%$, siendo superior en el nivel socioeconómico bajo (25\%).

Tabla 7. Estilo de vida en el grupo de mujeres heterosexuales

\begin{tabular}{lcccc}
\hline & \multicolumn{3}{c}{ Nivel socioeconómico } \\
\cline { 2 - 5 } & Bajo & Medio & Alto & $\begin{array}{c}\text { Total promedio } \\
\text { semanal }\end{array}$ \\
\hline Trabajar & 48.9 & 37.9 & 40.3 & 39.7 \\
Familia & 19.6 & 22.2 & 18.3 & 21.6 \\
Ir al cine & 2.0 & 2.4 & 2.2 & 2.3 \\
Salón de belleza & 2.5 & 3.8 & 1.5 & 3.6 \\
Ir al restaurante & 5.3 & 6.4 & 5.4 & 6.2 \\
Dormir & 40.2 & 42.1 & 46.3 & 42.2 \\
Estudiar & 18.8 & 21.7 & 25.8 & 21.9 \\
Hacer deporte & 8.8 & 5.4 & 8.7 & 6.0 \\
Internet & 11.8 & 14.0 & 19.8 & 14.3 \\
Ir a sauna & 7.0 & 4.6 & 1.0 & 4.4 \\
Actividades extremas & 10.0 & 6.4 &. & 6.7 \\
Ver televisión & 8.6 & 11.8 & 8.5 & 11.1 \\
Ir a video bares & 7.0 & 6.0 & 6.0 & 6.1 \\
Ir al gimnasio & 14.0 & 4.9 & 8.0 & 5.9 \\
Ir de compras & 4.5 & 4.5 & 6.5 & 4.6 \\
Ir a cafés & 7.8 & 5.2 & 6.3 & 5.6 \\
Estar solo & 15.0 & 12.7 & 10.8 & 12.8 \\
Tiempo en pareja & 12.7 & 14.1 & 18.2 & 14.3 \\
Leer & 6.0 & 8.3 & 13.4 & 8.7 \\
Caminar & 18.1 & 7.5 & 6.4 & 9.0 \\
Ir a bares & 10.1 & 8.9 & 8.7 & 9.0 \\
Escuchar música & 18.9 & 18.5 & 19.3 & 18.6 \\
Practicar su hobbie & 7.7 & 12.5 & 9.1 & 11.4 \\
\hline & & & & \\
\hline
\end{tabular}

La Tabla 8 presenta el patrón general de gastos promedio para el grupo de las mujeres heterosexuales, en el que se resalta en primer lugar los gastos de educación, posteriormente cuota de vivienda, préstamos bancarios, arriendo, tarjetas de crédito, viajes, cuota de ahorro, rumba, combos de telefonía, Internet y TV, transporte, ropa, abarrotes, calzado y productos cárnicos, entre otros. 
Tabla 8. Patrón general mensual de los gastos promedio en las mujeres heterosexuales

\begin{tabular}{|c|c|c|c|c|}
\hline \multirow{3}{*}{ Arriendo } & \multicolumn{4}{|c|}{ Nivel socioeconómico } \\
\hline & Bajo & Medio & Alto & Total promedio \\
\hline & $\$ 200.000$ & $\$ 410.952$ & $\$ 600.000$ & $\$ 383.509$ \\
\hline Cuota vivienda & $\$ 510.000$ & $\$ 706.667$ & $\$ 40.000$ & $\$ 656.190$ \\
\hline Energía eléctrica & $\$ 41.083$ & $\$ 66.946$ & $\$ 105.000$ & $\$ 66.054$ \\
\hline Agua/alcantarillado & $\$ 48.333$ & $\$ 90.620$ & $\$ 145.714$ & $\$ 89.267$ \\
\hline Gas & $\$ 18.545$ & $\$ 44.297$ & $\$ 50.000$ & $\$ 41.113$ \\
\hline Educación & $\$ 212.500$ & $\$ 980.912$ & $\$ 840.000$ & $\$ 929.519$ \\
\hline Productos cárnicos & $\$ 56.667$ & $\$ 110.049$ & $\$ 82.500$ & $\$ 100.299$ \\
\hline Productos lácteos & $\$ 44.733$ & $\$ 93.442$ & $\$ 35.000$ & $\$ 84.643$ \\
\hline Frutas y verduras & $\$ 57.917$ & $\$ 105.195$ & $\$ 57.000$ & $\$ 96.596$ \\
\hline Abarrotes & $\$ 112.833$ & $\$ 114.838$ & $\$ 53.333$ & $\$ 110.267$ \\
\hline Licores & $\$ 42.222$ & $\$ 89.222$ & $\$ 100.000$ & $\$ 82.966$ \\
\hline Cigarrillos & $\$ 55.000$ & $\$ 34.141$ & $\$ 47.000$ & $\$ 37.744$ \\
\hline Aseo para el hogar & $\$ 59.615$ & $\$ 106.000$ & $\$ 76.667$ & $\$ 98.051$ \\
\hline Aseo personal & $\$ 40.714$ & $\$ 61.311$ & $\$ 72.778$ & $\$ 59.673$ \\
\hline Productos para su pareja & $\$ 35.833$ & $\$ 65.789$ & $\$ 90.000$ & $\$ 63.511$ \\
\hline Ropa & $\$ 51.818$ & $\$ 124.028$ & $\$ 106.667$ & $\$ 113.933$ \\
\hline Calzado & $\$ 61.667$ & $\$ 110.565$ & $\$ 93.333$ & $\$ 103.506$ \\
\hline$C D$ & $\$ 37.500$ & $\$ 78.219$ & $\$ 100.000$ & $\$ 76.514$ \\
\hline Viajes & $\$ 80.000$ & $\$ 237.045$ & $\$ 142.000$ & $\$ 224.400$ \\
\hline Salud & $\$ 34.200$ & $\$ 109.145$ & $\$ 91.667$ & $\$ 99.094$ \\
\hline Transporte & $\$ 69.333$ & $\$ 137.809$ & $\$ 155.556$ & $\$ 130.458$ \\
\hline Préstamos bancarios & $\$ 308.000$ & $\$ 375.000$ & $\$ 1.266 .667$ & $\$ 445.909$ \\
\hline Tarjetas de crédito & $\$ 200.000$ & $\$ 252.308$ & $\$ 180.000$ & $\$ 239.375$ \\
\hline Cuota de ahorro & $\$ 37.143$ & $\$ 234.474$ & $\$ 115.000$ & $\$ 194.900$ \\
\hline Rumba & $\$ 175.000$ & $\$ 105.444$ & $\$ 342.222$ & $\$ 145.982$ \\
\hline Clubs & $\$ 40.000$ & $\$ 53.750$ & $\$ 75.000$ & $\$ 54.286$ \\
\hline Televisión & $\$ 15.000$ & $\$ 74.533$ & $\$ 48.000$ & $\$ 66.444$ \\
\hline Tv cable & $\$ 23.000$ & $\$ 64.435$ & $\$ 390.000$ & $\$ 79.233$ \\
\hline Internet & $\$ 27.400$ & $\$ 66.960$ & $\$ 70.000$ & $\$ 60.677$ \\
\hline Combos & $\$ 224.000$ & $\$ 119.216$ & $\$ 290.000$ & $\$ 145.178$ \\
\hline Otros gastos & $\$ 30.000$ & $\$ 107.000$ & $\$ 500.000$ & $\$ 152.143$ \\
\hline
\end{tabular}

Estilo de vida y prácticas de consumo en el grupo de gays

En la Tabla 9 se presentan las actividades con mayor dedicación de tiempo por semana, para el grupo de los gay, las cuales son: dormir (41.8 horas), trabajar (38.7 horas), tiempo en pareja (28 horas) y estudiar (20.4 horas). Las principales correlaciones se han identificado con estudiar y tiempo en familia ( $r$ : 0.38), estudiar y leer $(r$ : $0.41)$, ir a bares y estudiar ( $r: 0.41)$, ir a bares y actividades extremas ( $r$ : 0.78), y bares e ir al gimnasio ( $r$ : 0.54), entre otras, trabajar y caminar (r: 0.47). Los principales hobbies corresponden a la práctica de deportes específicos, la música y actividades manuales. Las prácticas deportivas de mayor frecuencia en los gay son los juegos de mesa con un $25.2 \%$, siendo superior en el nivel so- 
cioeconómico bajo (38.1\%), caminatas (22.7\%) con superioridad en el nivel económico alto (35.7\%), ciclismo con el $20.9 \%$, superior en el nivel medio (24.2\%).

Tabla 9. Estilo de vida en el grupo de gays

\begin{tabular}{lcccc}
\hline & \multicolumn{3}{c}{ Nivel Socioeconómico } \\
\cline { 2 - 5 } & Bajo & Medio & Alto & $\begin{array}{c}\text { Total promedio } \\
\text { semanal }\end{array}$ \\
\hline Trabajar & 34.7 & 39.9 & 33.5 & 38.7 \\
Familia & 16.6 & 16.0 & 16.8 & 16.1 \\
Ir al cine & 2.3 & 2.8 & 6.5 & 3.2 \\
Salón de belleza & 6.1 & 3.3 & 3.4 & 3.7 \\
Ir al restaurante & 8.9 & 6.3 & 11.2 & 7.1 \\
Dormir & 34.1 & 42.6 & 45.2 & 41.8 \\
Estudiar & 23.8 & 19.9 & 22.8 & 20.4 \\
Hacer deporte & 6.8 & 7.9 & 5.6 & 7.6 \\
Internet & 14.3 & 14.6 & 20.2 & 15.1 \\
Ir a saunas & 3.7 & 3.2 & 2.5 & 3.2 \\
Actividades extremas & 6.3 & 5.3 & 1.5 & 5.1 \\
Ver televisión & 10.6 & 13.6 & 8.8 & 12.7 \\
Ir a video bares & 9.4 & 7.5 & 2.5 & 7.3 \\
Ir al gimnasio & 10.0 & 13.2 & 5.6 & 11.8 \\
Ir de compras & 5.2 & 4.9 & 4.1 & 4.9 \\
Ir a cafés & 5.1 & 4.9 & 5.5 & 5.0 \\
Estar solo & 12.9 & 12.3 & 12.8 & 12.4 \\
Tiempo en pareja & 31.9 & 16.1 & 25.3 & 28.0 \\
Leer & 9.5 & 7.7 & 7.7 & 7.8 \\
Caminar & 12.4 & 8.1 & 5.8 & 8.4 \\
Ir a bares & 13.9 & 9.3 & 9.2 & 10.0 \\
Escuchar música & 20.5 & 16.7 & 18.0 & 17.3 \\
Practicar su hobbie & 18.0 & 9.9 & 26.2 & 11.8 \\
\hline
\end{tabular}

Tabla 10. Patrón general de gastos mensual promedio en el grupo de gays

\begin{tabular}{lcccc}
\hline & \multicolumn{4}{c}{ Nivel socioeconómico } \\
\cline { 2 - 5 } & Bajo & Medio & Alto & Total promedio \\
\hline Arriendo & $\$ 266.667$ & $\$ 364.262$ & $\$ 976.000$ & $\$ 393.333$ \\
Cuota vivienda & $\$ 176.667$ & $\$ 1.202 .625$ & $\$ 720.000$ & $\$ 1.024 .600$ \\
Energía eléctrica & $\$ 29.500$ & $\$ 53.049$ & $\$ 106.111$ & $\$ 54.605$ \\
Agua/alcantarillado & $\$ 46.786$ & $\$ 75.085$ & $\$ 134.111$ & $\$ 76.521$ \\
Gas & $\$ 36.444$ & $\$ 65.716$ & $\$ 45.286$ & $\$ 60.819$ \\
Educación & $\$ 657.000$ & $\$ 733.966$ & $\$ 1.196 .000$ & $\$ 768.565$ \\
Productos cárnicos & $\$ 83.333$ & $\$ 84.455$ & $\$ 128.375$ & $\$ 88.566$ \\
Productos lácteos & $\$ 32.273$ & $\$ 55.171$ & $\$ 105.700$ & $\$ 57.631$ \\
Frutas y verduras & $\$ 40.000$ & $\$ 51.053$ & $\$ 138.333$ & $\$ 58.158$ \\
\hline
\end{tabular}




\begin{tabular}{lcccc}
\hline & \multicolumn{4}{c}{ Nivel socioeconómico } \\
\cline { 2 - 5 } & Bajo & Medio & Alto & Total promedio \\
\hline Abarrotes & $\$ 56.200$ & $\$ 84.917$ & $\$ 121.667$ & $\$ 85.396$ \\
\hline Licores & $\$ 95.455$ & $\$ 120.958$ & $\$ 112.917$ & $\$ 116.947$ \\
Cigarrillos & $\$ 51.143$ & $\$ 50.345$ & $\$ 48.833$ & $\$ 50.284$ \\
Aseo para el hogar & $\$ 35.357$ & $\$ 58.169$ & $\$ 88.000$ & $\$ 57.960$ \\
Aseo personal & $\$ 40.000$ & $\$ 68.557$ & $\$ 102.000$ & $\$ 67.787$ \\
Productos para su pareja & $\$ 50.556$ & $\$ 110.225$ & $\$ 88.125$ & $\$ 97.702$ \\
Ropa & $\$ 144.000$ & $\$ 224.226$ & $\$ 202.500$ & $\$ 211.036$ \\
Calzado & $\$ 125.000$ & $\$ 150.171$ & $\$ 154.444$ & $\$ 148.034$ \\
CD & $\$ 27.500$ & $\$ 98.891$ & $\$ 58.857$ & $\$ 85.083$ \\
Viajes & $\$ 245.714$ & $\$ 338.854$ & $\$ 926.667$ & $\$ 411.328$ \\
Salud & $\$ 80.800$ & $\$ 149.946$ & $\$ 126.875$ & $\$ 139.640$ \\
Transporte & $\$ 63.188$ & $\$ 133.115$ & $\$ 231.818$ & $\$ 132.846$ \\
Préstamos bancarios & $\$ 276.667$ & $\$ 942.345$ & $\$ 3.233 .333$ & $\$ 1.081 .657$ \\
Tarjetas de crédito & $\$ 40.000$ & $\$ 639.488$ & $\$ 936.667$ & $\$ 664.146$ \\
Cuota de ahorro & $\$ 87.500$ & $\$ 458.659$ & $\$ 741.667$ & $\$ 462.843$ \\
Rumba & $\$ 128.333$ & $\$ 191.800$ & $\$ 188.846$ & $\$ 183.800$ \\
Club & $\$ 70.000$ & $\$ 89.731$ & $\$ 183.333$ & $\$ 105.088$ \\
Televisión & $\$ 35.500$ & $\$ 56.607$ & $\$ 30.000$ & $\$ 53.242$ \\
Tv cable & $\$ 21.250$ & $\$ 45.458$ & $\$ 80.000$ & $\$ 43.310$ \\
Internet & $\$ 35.714$ & $\$ 49.064$ & $\$ 80.000$ & $\$ 47.814$ \\
Combos & $\$ 30.000$ & $\$ 105.048$ & $\$ 130.000$ & $\$ 106.571$ \\
Otros gastos & $\$ 312.400$ & $\$ 131.438$ & $\$ 587.500$ & $\$ 240.600$ \\
\hline
\end{tabular}

La Tabla 10 presenta el patrón general de gastos promedio para el grupo de los gay, se resalta en primer lugar los gastos de préstamos bancarios, seguido por la cuota de vivienda, educación, tarjetas de crédito, cuota de ahorro, viajes, arriendo, ropa, rumba, calzado, salud, transporte, licores, combos de telefonía, Internet y TV y visitas a clubes nocturnos.

\section{Estilo de vida y prácticas de consumo en el grupo de hombres bisexuales}

En la Tabla 11 se muestra que las actividades con mayor dedicación de tiempo semanal para el grupo de los hombre bisexuales son: trabajar (44.8 horas), seguido por dormir (42.6 horas), estudiar
(24.3 horas), tiempo en pareja (15.8), escuchar música (14.4), tiempo en familia (14.7 horas), Internet (14.6 horas). Adicionalmente, se resalta la correlación inversa entre el tiempo dedicado al trabajo y el tiempo en pareja ( $r$ : -0.55), a diferencia de la correlación positiva entre el tiempo dedicado al trabajo y caminar ( $r$ : 0.45). De otra parte se resalta la correlación entre hacer deporte e ir a cine ( $r$ : 0.59), así como la correlación entre ir a video bares y dormir ( $r: 0.62)$, estudiar y hacer deporte ( $r: 0.60)$, entre otras. Los principales hobbies corresponden a la práctica de deportes específicos, la música y actividades manuales. Las prácticas deportivas de mayor frecuencia en los hombres bisexuales son las caminatas (29.3\%), seguidas por el voleibol (22\%), así como los aeróbicos, las pesas y el fútbol cada uno con un $19.5 \%$. 
Tabla 11. Estilo de vida para el grupo de los hombres bisexuales

\begin{tabular}{lcccc}
\hline & \multicolumn{3}{c}{ Nivel socioeconómico } \\
\cline { 2 - 5 } & Bajo & Medio & Alto & $\begin{array}{c}\text { Total promedio } \\
\text { semanal }\end{array}$ \\
\hline Trabajar & 48.7 & 44.8 & 30.8 & 44.8 \\
Familia & 20.3 & 14.0 & 14.1 & 14.7 \\
Ir al cine & 2.0 & 2.3 & 3.2 & 2.5 \\
Salón de belleza & 1.0 & 5.2 & 3.6 & 4.4 \\
Ir al restaurante & 9.7 & 9.7 & 8.4 & 9.4 \\
Dormir & 41.5 & 41.4 & 48.1 & 42.6 \\
Estudiar & 10.5 & 22.2 & 49.3 & 24.3 \\
Hacer deporte & 3.0 & 3.4 & 11.4 & 4.9 \\
Internet & 4.3 & 12.9 & 27.5 & 14.6 \\
Ir a saunas &. & 3.4 & 4.0 & 3.5 \\
Actividades extremas &. & 5.6 & 6.0 & 5.7 \\
Ver televisión & 11.5 & 14.4 & 12.6 & 13.9 \\
Ir a video bares &. & 5.9 & 4.0 & 5.8 \\
Ir al gimnasio &. & 7.9 & 11.4 & 9.3 \\
Ir de compras & 3.0 & 4.9 & 5.6 & 5.0 \\
Ir a cafés & 2.0 & 4.7 & 6.8 & 5.0 \\
Estar solo & 17.5 & 14.2 & 10.0 & 13.7 \\
Tiempo en pareja & 7.3 & 15.6 & 23.0 & 15.8 \\
Leer & 2.0 & 6.6 & 8.5 & 6.5 \\
Caminar & 18.0 & 9.6 & 7.8 & 9.6 \\
Ir a bares &. & 6.5 & 15.0 & 8.4 \\
Escuchar música & 20.0 & 12.8 & 29.4 & 15.4 \\
Practicar su hobbie & 4.5 & 4.6 & 30.0 & 8.5 \\
\hline & & & & \\
\hline
\end{tabular}

La Tabla 12 presenta el patrón general de gastos promedio para el grupo de los hombres bisexuales, en la cual se resalta en primer lugar cuota de ahorro, debido principalmente al nivel de ahorro reportado en el nivel socioeconómico alto que es significativamente alto $\left(\$ 6^{\prime} 000.000\right)$. Posteriormente, se encuentran gastos en educa- ción, arriendo, cuota de vivienda, préstamos bancarios, viajes, tarjetas de crédito y calzado, entre otros. Se resalta que en casi todos los casos, el nivel socioeconómico alto reporta cifras sensiblemente superiores para el grupo de los hombres bisexuales.

Tabla 12. Patrón general de gastos mensual para el grupo de los hombres bisexuales

\begin{tabular}{lcccr}
\hline & \multicolumn{4}{c}{ Nivel socioeconómico } \\
\cline { 2 - 5 } & Bajo & Medio & Alto & Total promedio \\
\hline Arriendo &. & $\$ 436.053$ & $\$ 950.000$ & $\$ 485.000$ \\
Cuota vivienda & $\$ 140.000$ & $\$ 210.500$ & $\$ 2.000 .000$ & $\$ 446.000$ \\
Energía eléctrica & $\$ 14.750$ & $\$ 45.158$ & $\$ 290.000$ & $\$ 68.731$ \\
Agua/alcantarillado & $\$ 37.000$ & $\$ 84.118$ & $\$ 250.000$ & $\$ 97.000$ \\
Gas & $\$ 9.750$ & $\$ 16.056$ & $\$ 55.000$ & $\$ 18.250$ \\
\hline
\end{tabular}




\begin{tabular}{lcccr}
\hline & \multicolumn{3}{c}{ Nivel socioeconómico } & \\
\cline { 2 - 5 } & Bajo & Medio & Alto & Total promedio \\
\hline Educación & $\$ 82.500$ & $\$ 790.000$ & $\$ 5.100 .000$ & $\$ 1.169 .211$ \\
Productos cárnicos & $\$ 250.00$ & $\$ 42.200$ & $\$ 202500$ & $\$ 65538$ \\
Productos lácteos & $\$ 25.667$ & $\$ 35.000$ & $\$ 97.500$ & $\$ 42.929$ \\
Frutas y verduras & $\$ 7.667$ & $\$ 37.857$ & $\$ 23.2500$ & $\$ 62.429$ \\
Abarrotes & $\$ 15.000$ & $\$ 37.895$ & $\$ 85.000$ & $\$ 38.958$ \\
Licores & $\$ 40.000$ & $\$ 63.450$ & $\$ 387.500$ & $\$ 106.393$ \\
Cigarrillos & $\$ 6.000$ & $\$ 29.464$ & $\$ 34.000$ & $\$ 28.917$ \\
Aseo para el hogar & $\$ 21.250$ & $\$ 37.316$ & $\$ 110.000$ & $\$ 43.231$ \\
Aseo personal & $\$ 14.250$ & $\$ 44.565$ & $\$ 165.000$ & $\$ 56.194$ \\
Productos para su pareja & $\$ 30.000$ & $\$ 42.727$ & $\$ 477.500$ & $\$ 143.529$ \\
Ropa & $\$ 56.667$ & $\$ 129.545$ & $\$ 340.000$ & $\$ 163.226$ \\
Calzado & $\$ 36.667$ & $\$ 106.500$ & $\$ 613.333$ & $\$ 204.138$ \\
Cd's & $\$ 6.000$ & $\$ 22.750$ & $\$ 532.500$ & $\$ 182.842$ \\
Viajes & $\$ 150.000$ & $\$ 148.583$ & $\$ 505.000$ & $\$ 255.650$ \\
Salud & $\$ 20.000$ & $\$ 99.667$ & $\$ 100.000$ & $\$ 95.000$ \\
Transporte & $\$ 103.333$ & $\$ 92.958$ & $\$ 207.000$ & $\$ 111.750$ \\
Préstamos bancarios &. & $\$ 350.000$ &. & $\$ 350.000$ \\
Tarjetas de crédito & $\$ 170.000$ & $\$ 215.000$ & $\$ 490.000$ & $\$ 253846$ \\
Cuota de ahorro & $\$ 200.000$ & $\$ 181.250$ & $\$ 6.000 .000$ & $\$ 1.240 .909$ \\
Rumba &. & $\$ 98.500$ & $\$ 355.000$ & $\$ 157.692$ \\
Club & $\cdot$ & $\$ 49.000$ & $\$ 210.000$ & $\$ 109.375$ \\
Televisión & $\$ 25.000$ & $\$ 33.000$ &. & $\$ 31.667$ \\
Tv cable & $\$ 25.000$ & $\$ 59.000$ &. & $\$ 54.750$ \\
Internet & $\$ 5.000$ & $\$ 52.500$ &. & $\$ 45.714$ \\
Combos & & $\$ 117.143$ & $\$ 147.500$ & $\$ 128.182$ \\
Otros gastos & $\$ 21.000$ & $\$ 38.000$ & $\$ 20.000 .000$ & $\$ 2.887 .286$ \\
\hline
\end{tabular}

\section{Estilo de vida y prácticas de consumo en el grupo de hombres heterosexuales}

La Tabla 13 indica las actividades con mayor dedicación de tiempo semanal para el grupo de los hombres heterosexuales, así: trabajar (44.6 horas), seguido por dormir (42.1 horas), estudiar (24 horas), tiempo en familia (19 horas), escuchar mú- sica (16.4) y tiempo en pareja (14.5). Se resaltan principalmente las siguientes correlaciones significativas al $99 \%$ : entre trabajar y tiempo en familia ( $r: 0.32)$, hacer deporte y estudiar ( $r: 0.44)$, ver televisión y dormir ( $r: 0,0.44)$. Los principales hobbies se relacionan con la música, los deportes y los videojuegos. Las prácticas deportivas de mayor frecuencia en los hombres heterosexuales son los juegos de mesa (26.8\%), seguidas por fútbol (23.9\%) y las caminatas (22.5\%).

Tabla 13. Estilo de vida en el grupo de los hombres heterosexuales

\begin{tabular}{lcccc}
\hline & \multicolumn{4}{c}{ Nivel socioeconómico } \\
\cline { 2 - 5 } & Bajo & Medio & Alto & $\begin{array}{c}\text { Total promedio } \\
\text { semanal }\end{array}$ \\
\hline Trabajar & 46.3 & 44.1 & 46.8 & 44.6 \\
Familia & 19.8 & 18.8 & 20.0 & 19.0 \\
\hline
\end{tabular}




\begin{tabular}{lcccc}
\hline & \multicolumn{3}{c}{ Nivel socioeconómico } \\
\cline { 2 - 5 } & Bajo & Medio & Alto & $\begin{array}{c}\text { Total promedio } \\
\text { semanal }\end{array}$ \\
\hline Ir al cine & & & 5.0 & 3.6 \\
Salón de belleza & 2.0 & 3.5 & 5.5 & 2.9 \\
Ir al restaurante & 2.0 & 2.4 & 13.0 & 5.8 \\
Dormir & 7.3 & 5.2 & 47.3 & 42.1 \\
Estudiar & 39.9 & 41.3 & 24.6 & 24.0 \\
Hacer deporte & 24.4 & 22.8 & 11.8 & 6.2 \\
Internet & 6.4 & 5.8 & 13.8 & 12.4 \\
Ir a saunas & 9.5 & 12.6 & 5.0 & 3.0 \\
Actividades extremas & 3.0 & 2.2 & 5.0 & 5.3 \\
Ver televisión &. & 5.3 & 10.1 & 10.0 \\
Ir a video bares & 10.7 & 9.9 & 4.3 & 4.9 \\
Ir al gimnasio & 6.0 & 4.8 & 26.8 & 10.6 \\
Ir de compras & 3.0 & 8.0 & 7.7 & 4.1 \\
Ir a cafés & 3.9 & 3.9 & 8.0 & 4.6 \\
Estar solo & 3.5 & 4.1 & 7.0 & 10.7 \\
Tiempo en pareja & 14.6 & 10.4 & 14.5 \\
Leer & 17.0 & 13.2 & 27.5 & 9.1 \\
Caminar & 5.8 & 9.4 & 9.6 & 7.8 \\
Ir a bares & 11.8 & 7.3 & 7.3 & 6.4 \\
Escuchar música & 3.4 & 6.4 & 12.8 & 16.4 \\
Practicar su hobbie & 15.6 & 16.1 & 21.8 & 11.1 \\
\hline & 7.5 & 11.9 & 8.0 & \\
\hline
\end{tabular}

Tabla 14. Patrón general de gastos mensual en el grupo de hombres heterosexuales

\begin{tabular}{lcccc}
\hline & \multicolumn{4}{c}{ Nivel socioeconómico } \\
\cline { 2 - 5 } & Bajo & Medio & Alto & $\begin{array}{c}\text { Total promedio } \\
\text { semanal }\end{array}$ \\
\hline Arriendo & $\$ 200.000$ & $\$ 677.196$ &. & $\$ 630.412$ \\
Cuota vivienda & $\$ 152.501$ & $\$ 375.714$ & $\$ 1.600 .000$ & $\$ 475.000$ \\
Energía eléctrica & $\$ 38.909$ & $\$ 64.042$ & $\$ 110.000$ & $\$ 63.511$ \\
Agua/alcantarillado & $\$ 46.636$ & $\$ 92.070$ & $\$ 143.333$ & $\$ 89.886$ \\
Gas & $\$ 32.833$ & $\$ 30.120$ & $\$ 44.667$ & $\$ 31.637$ \\
Educación & $\$ 522.125$ & $\$ 1.199 .050$ & $\$ 962.500$ & $\$ 1.110 .694$ \\
Productos cárnicos & $\$ 290.000$ & $\$ 76.972$ & $\$ 230.000$ & $\$ 106.369$ \\
Productos lácteos & $\$ 59.500$ & $\$ 48.787$ & $\$ 182.000$ & $\$ 57.378$ \\
Frutas y verduras & $\$ 56.000$ & $\$ 46.761$ & $\$ 206.000$ & $\$ 57.080$ \\
Abarrotes & $\$ 98.636$ & $\$ 67.069$ & $\$ 164.000$ & $\$ 78.311$ \\
Licores & $\$ 100.889$ & $\$ 64.157$ & $\$ 235.714$ & $\$ 81.965$ \\
Cigarrillos & $\$ 14.833$ & $\$ 39.864$ & $\$ 178.000$ & $\$ 53.723$ \\
Aseo para el hogar & $\$ 58.917$ & $\$ 54.620$ & $\$ 180.000$ & $\$ 62.330$ \\
Aseo personal & $\$ 64.143$ & $\$ 44.424$ & $\$ 236.667$ & $\$ 58.038$ \\
\hline
\end{tabular}




\begin{tabular}{lcccc}
\hline & \multicolumn{4}{c}{ Nivel socioeconómico } \\
\cline { 2 - 5 } & Bajo & Medio & Alto & $\begin{array}{c}\text { Total promedio } \\
\text { semanal }\end{array}$ \\
\hline Productos para su pareja & $\$ 51.875$ & $\$ 77.791$ & $\$ 241.667$ & $\$ 91.404$ \\
Ropa & $\$ 106.818$ & $\$ 112.090$ & $\$ 537.500$ & $\$ 150.988$ \\
Calzado & $\$ 146.250$ & $\$ 91.385$ & $\$ 442.857$ & $\$ 127.625$ \\
CD & $\$ 102.000$ & $\$ 63.838$ & $\$ 187.500$ & $\$ 78.739$ \\
Viajes & $\$ 307.500$ & $\$ 348.108$ & $\$ 4.325 .000$ & $\$ 994.082$ \\
Salud & $\$ 65.000$ & $\$ 99.767$ & $\$ 344.000$ & $\$ 112.041$ \\
Transporte & $\$ 81.154$ & $\$ 91.380$ & $\$ 385.714$ & $\$ 108.589$ \\
Préstamos bancarios & $\cdot$ & $\$ 469.524$ & $\$ 500.000$ & $\$ 473.333$ \\
Tarjetas de crédito & $\$ 85.000$ & $\$ 330.556$ & $\$ 420.000$ & $\$ 323.977$ \\
Cuota de ahorro & $\$ 90.000$ & $\$ 368.571$ & $\$ 1.100 .000$ & $\$ 465.862$ \\
Rumba & $\$ 66.250$ & $\$ 77.612$ & $\$ 280.000$ & $\$ 90.329$ \\
Clubs &. & $\$ 89.545$ & $\$ 150.000$ & $\$ 98.846$ \\
Televisión & $\$ 14.333$ & $\$ 63.077$ & $\$ 50.000$ & $\$ 53.706$ \\
Tv cable & $\$ 51.000$ & $\$ 4.5813$ &. & $\$ 46.632$ \\
Internet & $\$ 37.600$ & $\$ 51.833$ & $\$ 50.000$ & $\$ 49.806$ \\
Combos & $\$ 53.000$ & $\$ 121.550$ & $\$ 308.000$ & $\$ 142.114$ \\
Otros gastos & $\$ 100.000$ & $\$ 70.000$ & $\$ 146.667$ & $\$ 91.667$ \\
\hline
\end{tabular}

En la Tabla 14 se presenta el patrón general de gastos promedio para el grupo de hombres heterosexuales, cuyos principales gastos son para educación, viajes, arriendo, cuota de vivienda, préstamos bancarios, cuota de ahorro, tarjetas de crédito, ropa, combos de televisión, telefonía e Internet, calzado, salud, transporte y productos cárnicos.

\section{Estilo de vida y prácticas de consu- mo en el grupo de los transexuales}

La Tabla 15 indica que las actividades con mayor dedicación de tiempo por semana para el grupo de los transexuales son: dormir (48.6 horas), trabajar (46.7), tiempo en pareja (20.8), estudiar (19.7 horas) y escuchar música (16.0). Los principales hobbies se relacionan con la música, los deportes, pasear y actividades manuales. Las prácticas deportivas de mayor frecuencia en los transexuales son: caminatas (31.3\%), pilates y aeróbicos con el $28.1 \%$, principalmente.

Tabla 15. Estilo de vida en el grupo de los transexuales

\begin{tabular}{lcccc}
\hline & \multicolumn{4}{c}{ Nivel socioeconómico } \\
\cline { 2 - 5 } & Bajo & Medio & Alto & $\begin{array}{c}\text { Total promedio } \\
\text { semanal }\end{array}$ \\
\hline Trabajar & 45.8 & 43.1 & 44.2 & 46.7 \\
Familia & 12.0 & 9.4 & 9.6 & 9.9 \\
Ir al cine & 8.5 & 2.4 & 2.5 & 3.5 \\
Salón de belleza & 25.8 & 7.0 & 3.5 & 10.8 \\
Ir al restaurante & 6.0 & 6.1 & 3.8 & 5.5 \\
\hline
\end{tabular}




\begin{tabular}{lcccc}
\hline & \multicolumn{3}{c}{ Nivel socioeconómico } \\
\cline { 2 - 4 } & Bajo & Medio & Alto & $\begin{array}{c}\text { Total promedio } \\
\text { semanal }\end{array}$ \\
\hline Dormir & 44.3 & 47.4 & 48.3 & 48.6 \\
Estudiar & 23.5 & 24.1 & 4.3 & 19.7 \\
Hacer deporte & 16.3 & 4.2 & 4.0 & 7.0 \\
Internet & 7.8 & 8.3 & 5.7 & 7.4 \\
Ir a saunas & 3.8 & 3.1 & 5.0 & 3.4 \\
Actividades extremas &. & 2.8 &. & 2.8 \\
Ver televisión & 13.2 & 8.4 & 11.2 & 10.3 \\
Ir a video bares & 12.8 & 4.2 & 3.5 & 6.3 \\
Ir al gimnasio & 28.0 & 4.6 & 9.5 & 10.9 \\
Ir de compras & 6.7 & 10.2 & 4.6 & 8.1 \\
Ir a cafés & 5.5 & 3.1 & 2.5 & 3.6 \\
Estar solo & 14.9 & 6.6 & 7.7 & 9.7 \\
Tiempo en pareja & 42.0 & 13.1 & 3.5 & 20.8 \\
Leer & 9.6 & 6.6 & 2.8 & 6.6 \\
Caminar & 20.9 & 5.5 & 1.8 & 9.1 \\
Ir a bares & 8.2 & 6.1 & 5.6 & 6.5 \\
Escuchar música & 27.3 & 13.6 & 4.8 & 16.0 \\
Practicar su hobbie & 14.0 & 6.7 & 3.3 & 8.1 \\
\hline
\end{tabular}

En la Tabla 16 se presenta el patrón general de gastos promedio para el grupo de transexuales, en el cual se encuentra en primer lugar gastos de educación, seguido por arriendo, viajes, cuota de vivienda, tarjetas de crédito, préstamos bancarios, rumba, cuota de ahorro, ropa, calzado, transporte y combos de telefonía, Internet y televisión.

Tabla 16. Patrón general de gastos mensual para el grupo de los transexuales

\begin{tabular}{lcccc}
\hline & \multicolumn{4}{c}{ Nivel socioeconómico } \\
\cline { 2 - 5 } & Bajo & Medio & Alto & $\begin{array}{c}\text { Total promedio } \\
\text { mensual }\end{array}$ \\
\hline Arriendo & $\$ 270.000$ & $\$ 758.333$ & $\$ 733.333$ & $\$ 632.500$ \\
Cuota vivienda & $\$ 176.000$ & $\$ 240.000$ & $\$ 782.000$ & $\$ 439.167$ \\
Energía eléctrica & $\$ 46.667$ & $\$ 75.467$ & $\$ 50.000$ & $\$ 63.923$ \\
Agua/alcantarillado & $\$ 48.571$ & $\$ 122.643$ & $\$ 98.000$ & $\$ 97.962$ \\
Gas & $\$ 38.250$ & $\$ 37.357$ & $\$ 26.667$ & $\$ 36.000$ \\
Educación & $\$ 90.000$ & $\$ 858.750$ & $\$ 550.000$ & $\$ 633.846$ \\
Productos cárnicos & $\$ 40.000$ & $\$ 67.000$ & $\$ 183.333$ & $\$ 72.783$ \\
Productos lácteos & $\$ 53.571$ & $\$ 39.133$ & $\$ 173.333$ & $\$ 59.280$ \\
Frutas y verduras & $\$ 160.714$ & $\$ 43.462$ & $\$ 57.500$ & $\$ 80.000$ \\
Abarrotes & $\$ 41.429$ & $\$ 64.167$ & $\$ 46.667$ & $\$ 54.545$ \\
Licores & $\$ 65.000$ & $\$ 108.182$ & $\$ 76.000$ & $\$ 91.500$ \\
Cigarrillos & $\$ 52.000$ & $\$ 25.455$ & $\$ 72.500$ & $\$ 40.333$ \\
Aseo para el hogar & $\$ 37.857$ & $\$ 38.286$ & $\$ 82.500$ & $\$ 45.240$ \\
\hline
\end{tabular}




\begin{tabular}{lcccc}
\hline & \multicolumn{4}{c}{ Nivel socioeconómico } \\
\cline { 2 - 5 } & Bajo & Medio & Alto & $\begin{array}{c}\text { Total promedio } \\
\text { mensual }\end{array}$ \\
\hline Aseo personal & $\$ 52.857$ & $\$ 53.625$ & $\$ 100.000$ & $\$ 60.296$ \\
Productos para su pareja & $\$ 60.000$ & $\$ 52.500$ & $\$ 50.000$ & $\$ 54.118$ \\
Ropa & $\$ 101.667$ & $\$ 129.583$ & $\$ 420.000$ & $\$ 185.435$ \\
Calzado & $\$ 128.000$ & $\$ 95.000$ & $\$ 300.000$ & $\$ 130.455$ \\
CD & $\$ 60.000$ & $\$ 40.714$ & $\$ 75.000$ & $\$ 49.500$ \\
Viajes & $\$ 75.000$ & $\$ 588.750$ & $\$ 566.667$ & $\$ 504.615$ \\
Salud & $\$ 40.625$ & $\$ 65.000$ & $\$ 230.000$ & $\$ 86.136$ \\
Transporte & $\$ 87.143$ & $\$ 103.000$ & $\$ 233.333$ & $\$ 127.852$ \\
Préstamos bancarios & $\$ 70.000$ & $\$ 135.000$ & $\$ 1.000 .000$ & $\$ 335.000$ \\
Tarjetas de crédito &. & $\$ 260.000$ & $\$ 460.000$ & $\$ 360.000$ \\
Cuota de ahorro & $\$ 60.000$ & $\$ 139.375$ & $\$ 743.333$ & $\$ 266.538$ \\
Rumba & $\$ 130.000$ & $\$ 133.333$ & $\$ 900.000$ & $\$ 303.333$ \\
Club & $\$ 140.000$ & $\$ 69.625$ & $\$ 73.333$ & $\$ 81.308$ \\
Televisión & $\$ 30.000$ & $\$ 34.000$ &. & $\$ 32.400$ \\
Tv cable & $\$ 20.000$ & $\$ 101.667$ & $\$ 130.000$ & $\$ 91.000$ \\
Internet & $\$ 22.500$ & $\$ 55.000$ & $\$ 80.000$ & $\$ 40.000$ \\
Combos & $\$ 100.000$ & $\$ 116.667$ & $\$ 87.750$ & $\$ 104.636$ \\
Otros gastos & $\$ 106.000$ & $\$ 25.000$ & $\$ 52.000$ & $\$ 72.250$ \\
\hline
\end{tabular}

\section{Discusión}

Los resultados de la presente investigación demuestran que existen muchas más semejanzas que diferencias entre mujeres y hombres homosexuales, en comparación con sus contrapartes heterosexuales. Esto puede indicar que el consumo de diferentes categorías de productos pareciera estar relacionado con variables de tipo demográfico, más que con la orientación sexual como tal. Como era lógico esperar, el consumo entre hombres y mujeres fue diferente, pero comparando cada grupo con los y las heterosexuales, las diferencias fueron mínimas. Lo anterior implica que, como se afirmó en la parte inicial del artículo, la edad, el promedio de ingresos, la educación, el nivel ocupacional y las experiencias previas de consumo, son las variables que mejor predicen los gastos de la población LGBT y que lo mismo se puede afirmar para las personas heterosexuales.

En este sentido, el "mercado rosa" no difiere fundamentalmente del mercado que se puede definir para diferentes subgrupos de edad y para los diferentes estratos. Probablemente el establecimien- to de un "mercado rosa" tiene sentido en relación con el manejo de los estereotipos asociados con los medios de comunicación, es decir, con la necesidad de segmentar el mix de comunicaciones para la población LGBT, que en muchos países latinoamericanos todavía experimenta el rechazo proveniente de los mass media.

En lo que se refiere al estilo de vida, el estudio muestra que existen algunas diferencias en el estilo de vida entre los grupos del colectivo LGBT, y entre éste y los heterosexuales; no obstante, estas diferencias son específicas y no pueden atribuirse exclusivamente a la orientación sexual. Se encontraron diferencias en las actividades asociadas a los espacios de homosocialización. De tal manera, los hombres gay muestran predominio de algunas actividades de esparcimiento nocturno, y los hombres bisexuales gastan mucho más dinero que los demás grupos estudiados. Así, las prácticas sociales que desarrollan los grupos humanos como se evidenció con los resultados de esta investigación muestran que aunque se enmarcan en contextos sociales específicos atienden en la mayor parte a la satisfacción de necesidades ma- 
teriales y afectivas al margen de la orientación sexual de las personas.

Es importante, por lo anterior, que futuras investigaciones sobre consumo se realicen con muestras más grandes que permitan contrastar los resultados en categorías específicas de productos y servicios.

\section{Referencias}

Alvarado, G; Botero, M. M., Giraldo, M. \& Dávila, J. (2005). Compra impulsiva en el homosexual masculino en la ciudad de Barranquilla (Colombia): Un estudio descriptivo. Psicología desde el Caribe, 16, 148-177.

Barrea, E. \& Olivera, L. (2004). Mujeres bisexuales y lesbianas, ¿cómo viven su sexualidad? Archivos Hispanoamericanos de Sexología, 10, (1), 105-130.

Burnett, J. (2000). Gays: feelings about advertising and media used. Journal of Advertising Research, 40 (2), 75-84.

Giraldo, M. \& Alvarado, V. (2006). Compra impulsiva en el homosexual masculino. Pensamiento \& Gestión, 20, 125-164.

Jepsen, C. \& Jepsen, L. (2009). Does home ownership vary by sexual orientation? Regional Science and Urban Economics, 39, 307-315.

Moreno, M. C. (2005). La investigación cualitativa en marketing: el camino hacia una percepción social del mercado. Revista Colombiana de Marketing. 6, 68-85.

Morrison, M. A., Morrison, T. \& Sager, Ch. (2004). Does body satisfaction differ between gay men and lesbian women and heterosexual men and women? A meta-analytic review. Body Image, 1, 127-138.

O'Brien, J. (2001). Heterosexism and Homophobia. International Encyclopedia of the Social \& Behavioral Sciences. 6672-6676.

Ortiz-Hernández, L., Gómez, B. \& Valdez, J. (2009). The association of sexual orientation with self-rated health, and cigarette and alcohol use in Mexican adolescents and youths. Social Science \& Medicine, 69, 85-63.

Pizacani, B., Rohde, K., Bushore, C., Stark, M., Maher A, J., Dilley, J. \& Boysun, M. (2009). Smoking-related knowledge, attitudes and behaviors in the lesbian, gay and bisexual community: A population-based study from the U.S. Pacific Northwest. Preventive Medicine, 48, 555-561.

Tucker, J., Ellickson, P. \& Klein, D. (2008). Understanding differences in substance use among bisexual and heterosexual young women. Women's Health Issues, 18, 387-398.

Tuncay, L. \& Otnes, C. (2008). The Use of Persuasion Management Strategies by Identity-Vulnerable Consumers: The Case of Urban Heterosexual Male Shoppers. Journal of Retailing, 84 (4) 487-499.

Vandecasteele, B. \& Geuens, M. (2009). Revising the myth of gay consumer innovativeness. Journal of Business Research, 6, 134-144.

Vélez, G. A. (2002). Comportamiento del consumidor. Aplicación de casos latinoamericanos. Bogotá, Colombia: UNAD. 